\title{
U.S. Geological Survey Response to Chronic Wasting Disease
}

\section{The USGS is focused on the development \\ of early detection and effective response tools that promote an adaptive management approach to Chronic Wasting Disease.}

\section{Overview}

Chronic wasting disease (CWD), a fatal contagious neurological disease, affects free-ranging and captive cervids (members of the deer family) such as elk (Cervus elaphus), moose (Alces alces), white-tailed deer (Odocoileus virginianus), and mule deer (Odocoileus hemionus). It is transmitted directly through animal-to-animal contact, and indirectly through contact with objects or an environment contaminated with infectious material (including saliva, urine, feces, and carcasses of CWD-infected animals). CWD is not known to affect humans or livestock. CWD, similar to scrapie in sheep and bovine spongiform encephalopathy ( $\mathrm{mad}$ cow disease) in cows, is caused by prions - pathogenic agents that mostly consist of an abnormal, infectious form of a host protein primarily found in the brain and central nervous system tissues of mammals.

CWD was initially identified in captive animals in the late 1960s and in free-ranging animals in the 1980s. Since its initial identification in Colorado, CWD continues to spread and has affected cervids in 26 States in the United States and 3 Provinces in Canada, as well as in Finland, Norway, South Korea, and Sweden.

A white-tailed deer displaying clinical signs of chronic wasting disease including weight loss, poor body condition, and hypersalivation.

\section{Importance of Cervids}

Healthy cervid populations are critical to biodiversity - these species serve as a middle link in the food chain between the plants they consume and the predators that prey on them. Cervids are also a popular game species providing a valuable food source for many and considered Tribal cultural resources and traditional food sources across the United States (Great Lakes Indian Fish and Wildlife Commission, 2018).

Cervids are an integral and charismatic

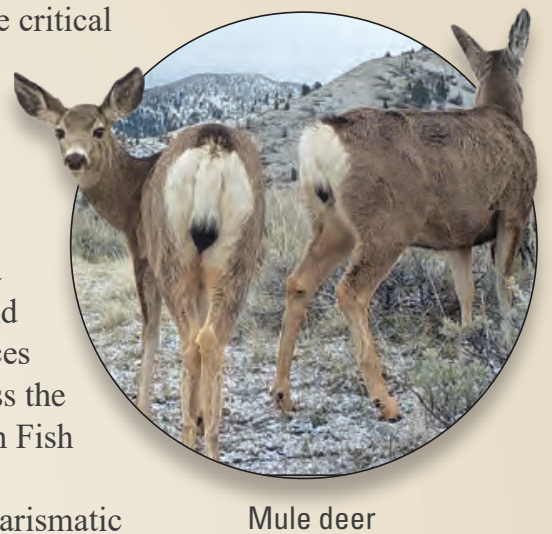
presence in the fabric of the U.S. landscape and an important element in the Nation's economy. Elk and deer are coveted among hunters and wildlife watchers throughout the country. According to the Outdoor Industry Association (2017), hunting and fishing contributed $\$ 63$ billion to U.S. retail spending in 2017 , and sales of permits and licenses for hunting and fishing support State wildlife agency budgets.

In 2016, according to the U.S. Fish and Wildlife Service and U.S. Census Bureau (2018), 9.2 million hunters pursued big game such as deer and elk, with deer being the most popular and attracting 8.1 million hunters across the United States. Deer were also among the most popular land mammals observed or photographed by 14 million people.

In areas of Colorado, Wisconsin, and Wyoming heavily affected by CWD, more than 40 percent of free-ranging cervids are infected. Scientists at the U.S. Geological Survey (USGS) Wyoming Cooperative Fish and Wildlife Research Unit (CRU) and their collaborators have documented CWD-associated population declines in white-tailed deer and mule deer. The effects of CWD on these biologically, culturally, and economically valuable animals could be devastating if measures are not taken to prevent its spread and persistence in wildlife and the environment.

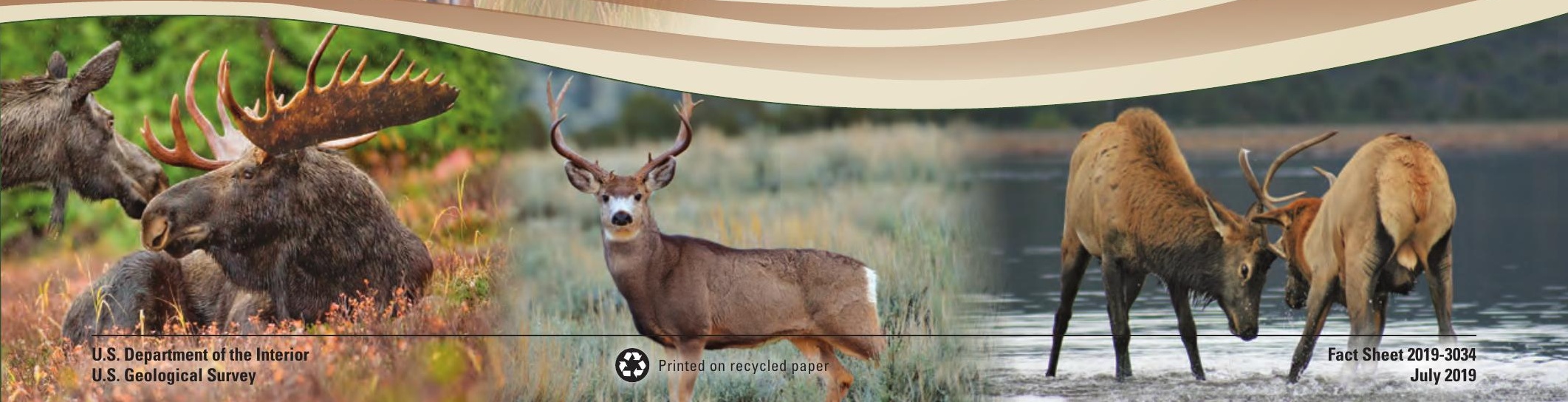




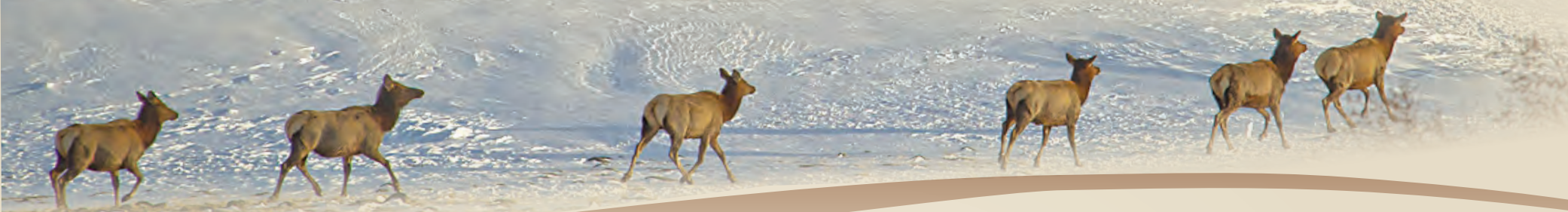

Natural Resources, 2019). Scientists at the USGS NWHC,

In collaboration with Federal and State agencies, ongoing USGS research is focused on developing rapid and sensitive diagnostic tests to detect prions in blood, feces, and the environment. These tests will potentially provide alternative methods for ante-mortem testing, help managers detect infection earlier in the disease course, and increase understanding of the risk and impacts of indirect transmission of CWD.

\section{In the Field}

The USGS Northern Prairie Wildlife Research Center is supporting National Park Service efforts to manage CWD at Wind Cave National Park in South Dakota. Past USGS work found that CWD was the leading cause of death in the park's elk population with infection rates up to 24 percent. Current efforts are focused on evaluating the effectiveness of reducing elk density on CWD-related mortality in that population. Results will guide CWD management at this and other national parks.

Scientists at the USGS Northern Rocky Mountain Science Center and the Wyoming CRU are collaborating with the Wyoming Game and Fish Department to map the risk of CWD spread from migrating mule deer to elk on feed grounds in western Wyoming. Movement data from Global Positioning System (GPS)-collared elk and mathematical models were used to develop disease risk maps for managers to focus surveillance strategies in elk.

USGS scientists at the Pennsylvania CRU are evaluating the effectiveness of targeted removal of white-tailed deer groups on CWD occurrence and distribution. Scientists are also implementing genetic research to understand the patterns of disease susceptibility and population connectivity across Maryland, Pennsylvania, and Virginia for targeted CWD mitigation strategies.

Since 2002, CWD prevalence in adult male white-tailed deer in western Wisconsin has increased to over 35 percent in 2019, from 8 to 10 percent (Wisconsin Department of

USGS lab technician prepares a DNA sample for genetic analysis. the Wisconsin Cooperative Wildlife Research Unit, and the Wisconsin Department of Natural Resources are developing a framework to understand relationships between CWD infection and deer demographic rates to guide management decisions. These generated, forecasted impacts of CWD on deer population dynamics will enable State natural resource managers to refine management decisions with improved accounting of the predicted effects of CWD.

\section{In the Laboratory}

Scientists at the USGS NWHC are working with experts in the medical industry to develop a process that optimizes the degradation of prions by existing or modified chemical solutions. Researchers have identified the temperature, $\mathrm{pH}$, and process steps that provide the greatest reduction in prion infectivity.

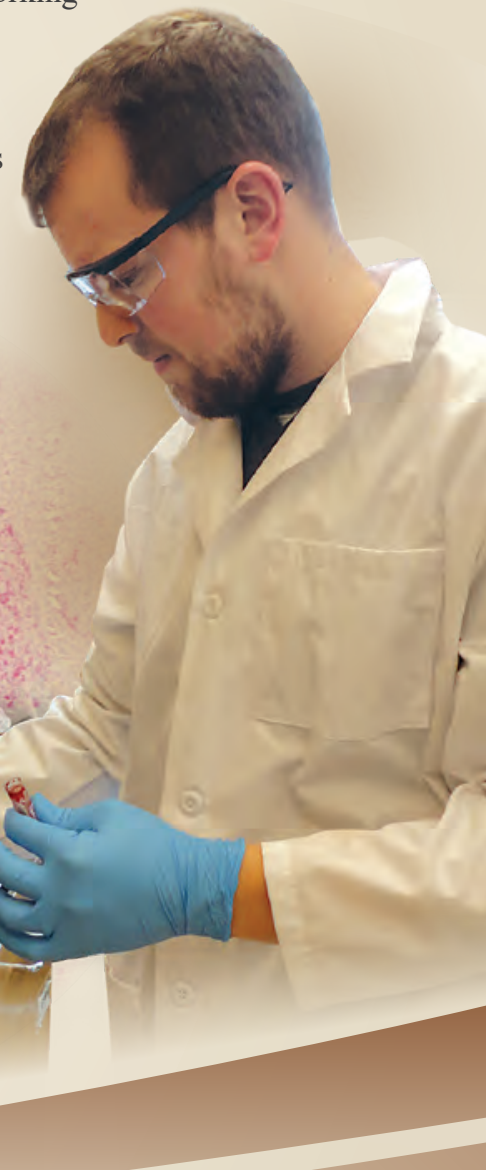

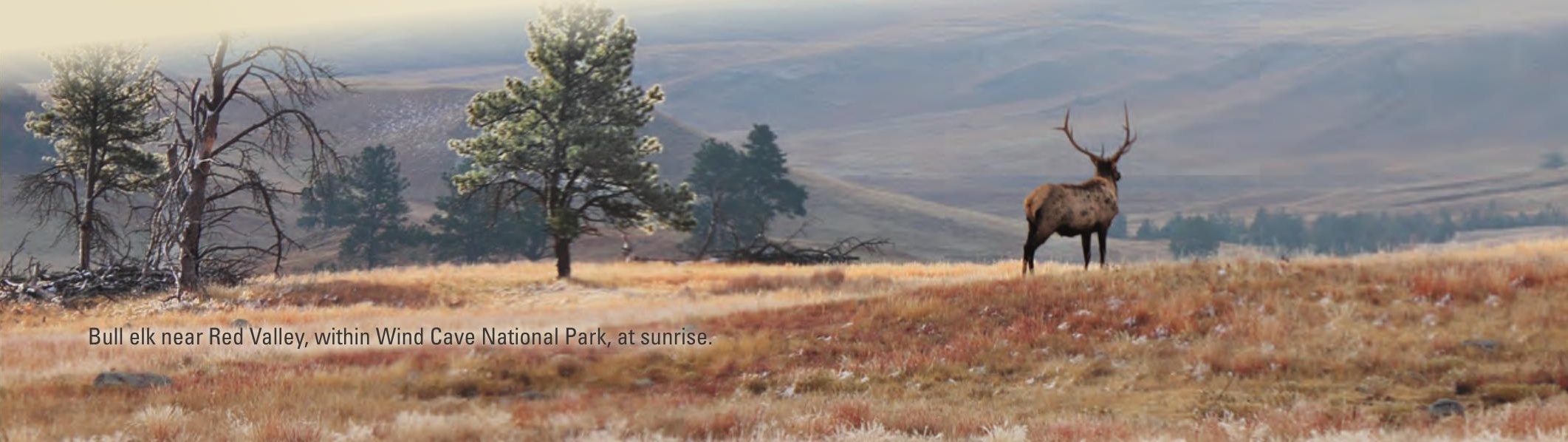




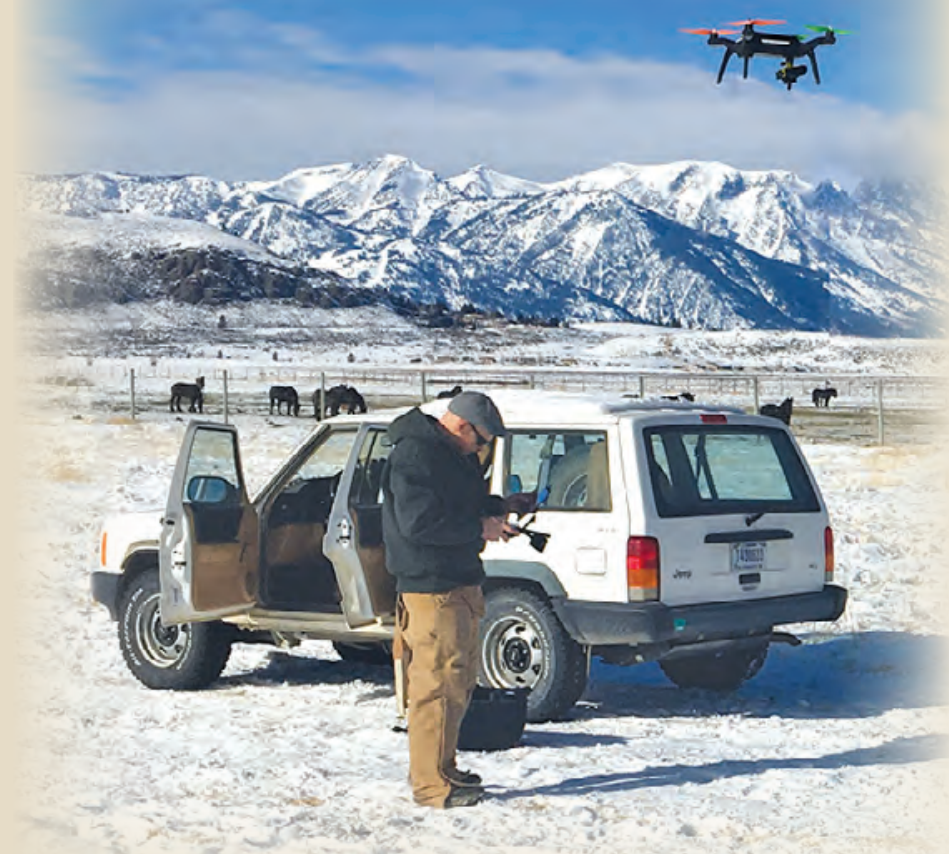

\section{References Cited}

Great Lakes Indian Fish and Wildlife Commission, 2018, Chronic wasting disease (CWD): Great Lakes Indian Fish and Wildlife Commission web page, accessed April 18, 2019, at https://data.glifwc.org/cwd/.

Outdoor Industry Association, 2017, The outdoor recreation economy: Outdoor Industry Association, 19 p., accessed April 18, 2019, at https://outdoorindustry.org/wp-content/ uploads/2017/04/OIA_RecEconomy_FINAL_Single.pdf.

Richards, B., 2019, Distribution of chronic wasting disease in North America: U.S. Geological Survey National Wildlife Health Center map, accessed June 11, 2019, at

https://www.usgs.gov/centers/nwhe/science/expandingdistribution-chronic-wasting-disease.

U.S. Fish and Wildlife Service and U.S. Census Bureau, 2018, 2016 national survey of fishing, hunting, and wildlifeassociated recreation: U.S. Fish and Wildlife Service and U.S. Census Bureau, 132 p., accessed April 18, 2019, at https://www.census.gov/content/dam/Census/library/ publications/2018/demo/fhw16-nat.pdf.

This work applies to prion decontamination for humans in hospitals as well as prion decontamination for animals in veterinary hospitals and at meat-processing facilities.

Prion-contaminated soil and plants, such as corn and other crops that deer feed on, may facilitate CWD transmission. Scientists at the USGS NWHC are working with those at the University of Wisconsin to study prion infectivity and prion uptake in plants to better understand what role crop plants play in transmission on the landscape.

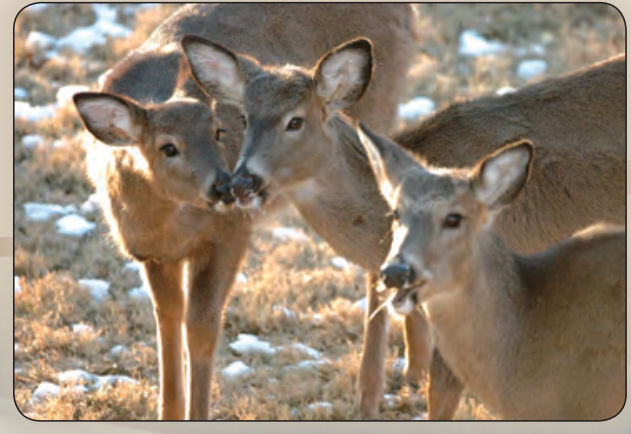

White-tailed deer fawns.

Wisconsin Department of Natural Resources, 2019, Prevalence \& surveillance: Wisconsin Department of Natural Resources web page, accessed April 18, 2019, at https://nnr.wi.gov/topic/ wildlifehabitat/prevalence.html.

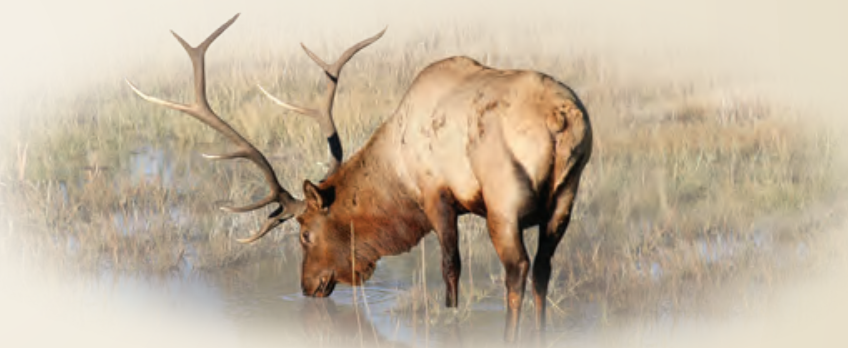

Elk on a feeding ground in Wyoming.

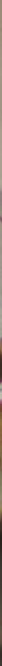

